\title{
Ultrastructure of the Tegument of Prosorhynchoides arcuatus (Linton, 1900) Bray, 1984 (Trematoda, Bucephalidae)
}

\author{
Simone C Cohen $/^{+}$, Anna Kohn, Ortrud M Barth ${ }^{*}$ \\ Laboratório de Helmintos Parasitos de Peixes, Departamento de Helmintologia *Laboratório de Ultraestrutura \\ Viral, Departamento de Virologia, Instituto Oswaldo Cruz, Av. Brasil 4365, 21045-900 \\ Rio de Janeiro, RJ, Brasil
}

The tegument of the adult form of Prosorhynchoides arcuatus (Linton, 1900) (Trematoda, Bucephalidae) from the intestine of Pomatomus saltator $(L$. from the Atlantic coast of the State of Rio de Janeiro, Brazil was studied by transmission electron microscopy. The tegument consists of two layers: an external, constituted by a syncytium, containing spines, unicilliated papillae, inclusion bodies and mitochondria and an internal, consisting of a muscular layer and mononucleated tegumental cells.

Key words: Prosorhynchoides arcuatus - fish parasites - Pomatomus saltator -

transmission electron microscopy - Brazil

The tegument of adult trematodes has been the subject of several investigations using electron microscopy. Nevertheless, there are few studies on the ultrastructure of helminth parasites of fishes, especially in the family Bucephalidae. The scanning electron microscope study of Prosorhynchoides arcuatus (Linton, 1900) Bray, 1984 was presented in a previous paper (Cohen et al. 1995). The aim of this paper is to investigate the ultrastructure of the tegument of $P$. arcuatus by transmission electron microscopy in thin sections.

\section{MATERIALS AND METHODS}

Specimens of $P$. arcuatus were recovered from the intestine of Pomatomus saltator L. (Pomatomidae), obtained from fishermen of "Praia da Ribeira, Ilha do Governador" and "Praia de Copacabana", Atlantic coast of the State of Rio de Janeiro, Brazil. The helminths were fixed in 2.5\% phosphate buffered glutaraldehyde and post fixed for $1 \mathrm{hr}$ in $1 \%$ osmium tetroxide in the same buffer. After dehydration through an increasing graded alcohol series, the material was embedded into araldite. Ultrathin sections were cut using a Reichert Ultracut-E microtome, contrasted with uranyl acetate and Reynold's solution of lead cit-

\footnotetext{
This paper is part of the thesis of Master degree of the first author.

The authors are Research Fellows "Conselho Nacional de Desenvolvimento Científico e Tecnológico - CNPq" ${ }^{+}$Corresponding author. Fax: 55-21-260.4866

Received 29 August 1995

Accepted 11 March 1996
}

rate and observed under a Zeiss EM 900 electron microscope.

\section{RESULTS}

The tegument of the adult form of $P$. arcuatus consists of two layers: an external that is constituted by a syncytium, where the spines are located, and an internal layer with mononucleated cells (Fig. 1).

Syncytium - The surface syncytium is irregularly-shaped, with digitiform projections, $8-10 \mu \mathrm{m}$ thick, covered by a thin layer of dense material. Internally, the syncytium is bounded by a plasma membrane, which rests on a regularly thickened basal lamina (Figs 3, 5). Spines are present inside the syncytium. These spines, when observed in light microscope preparations, seem to be single pointed and at higher magnification by scanning electron microscopy, they appear multipointed, with up to 30 points (Cohen et al. 1995). By transmission electron microscopy, these spines appear pointed and slightly recurved, in longitudinal sections, enclosed between the apical surface and internal plasma membrane (Fig. 3). The spine basis rests on the basal lamina in a more electrondense region, named basal plate. The spines have a refined crystalline structure, with units arranged in parallel, alternating dense and light lines in sections (Fig. 4).

The ground substance of the surface syncytium consists of granular material, more electrondense than of the mononucleated cells below and contains numerous inclusions bodies and mitochondria. Mitochondria are few, small, either round or slightly elongated (Figs 2, 3).

Two characteristic types of inclusion bodies 

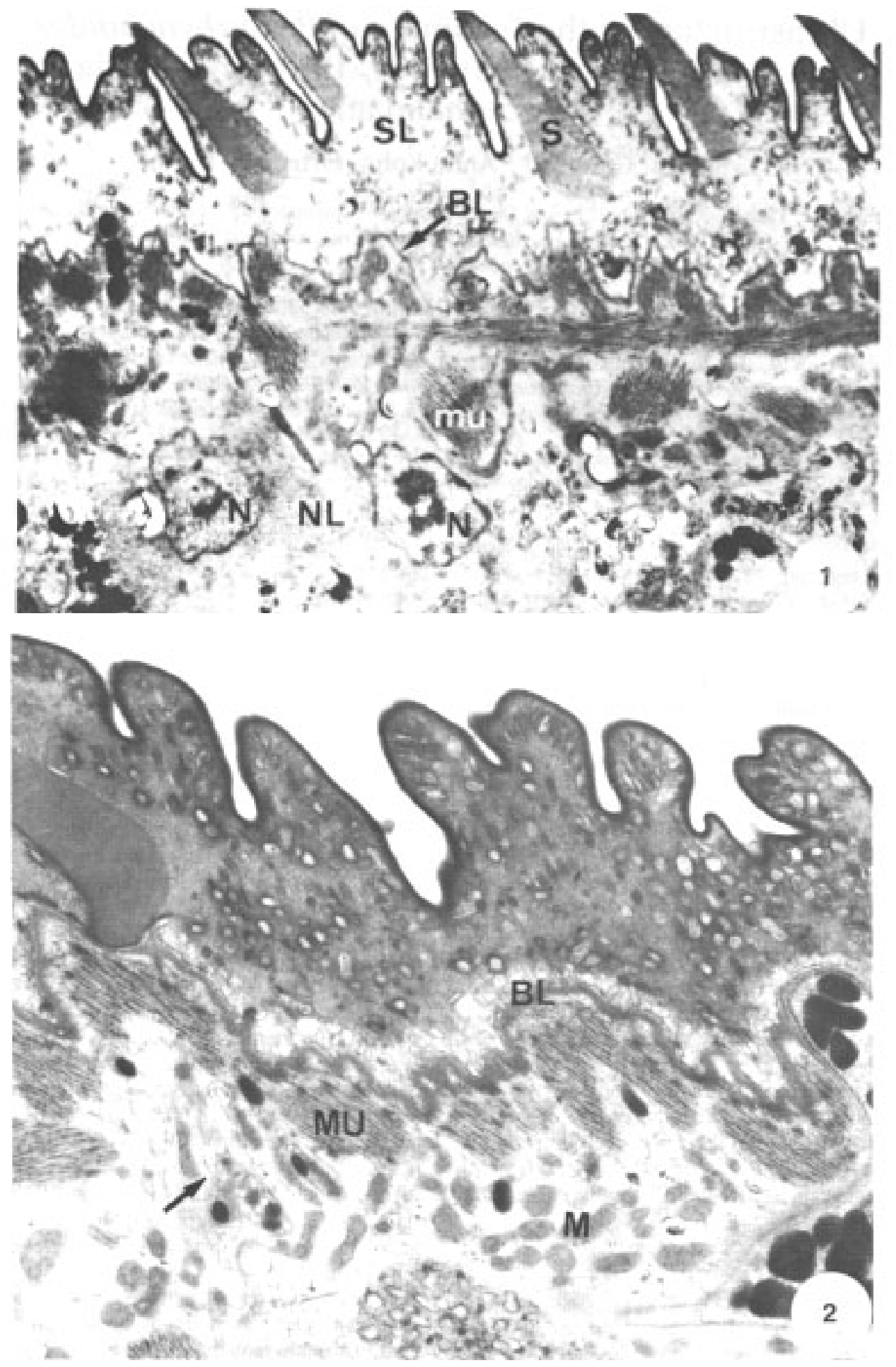

Fig. 1: body tegument showing external syncytial layer (SL), with spines (S), basal lamina (BL) and internal nucleated layer $(\mathrm{NL})$ with muscle fibres $(\mathrm{mu})$ and tegumental cells with nucleus $(\mathrm{N})$. X 8,000. Fig. 2: external syncytial layer with inclusion bodies and basal lamina (BL) following the outline of the underlying musculature (MU); cytoplasmatic processes (arrow) connecting the two layers and mitochondria (M) are observed. X 15,000. 

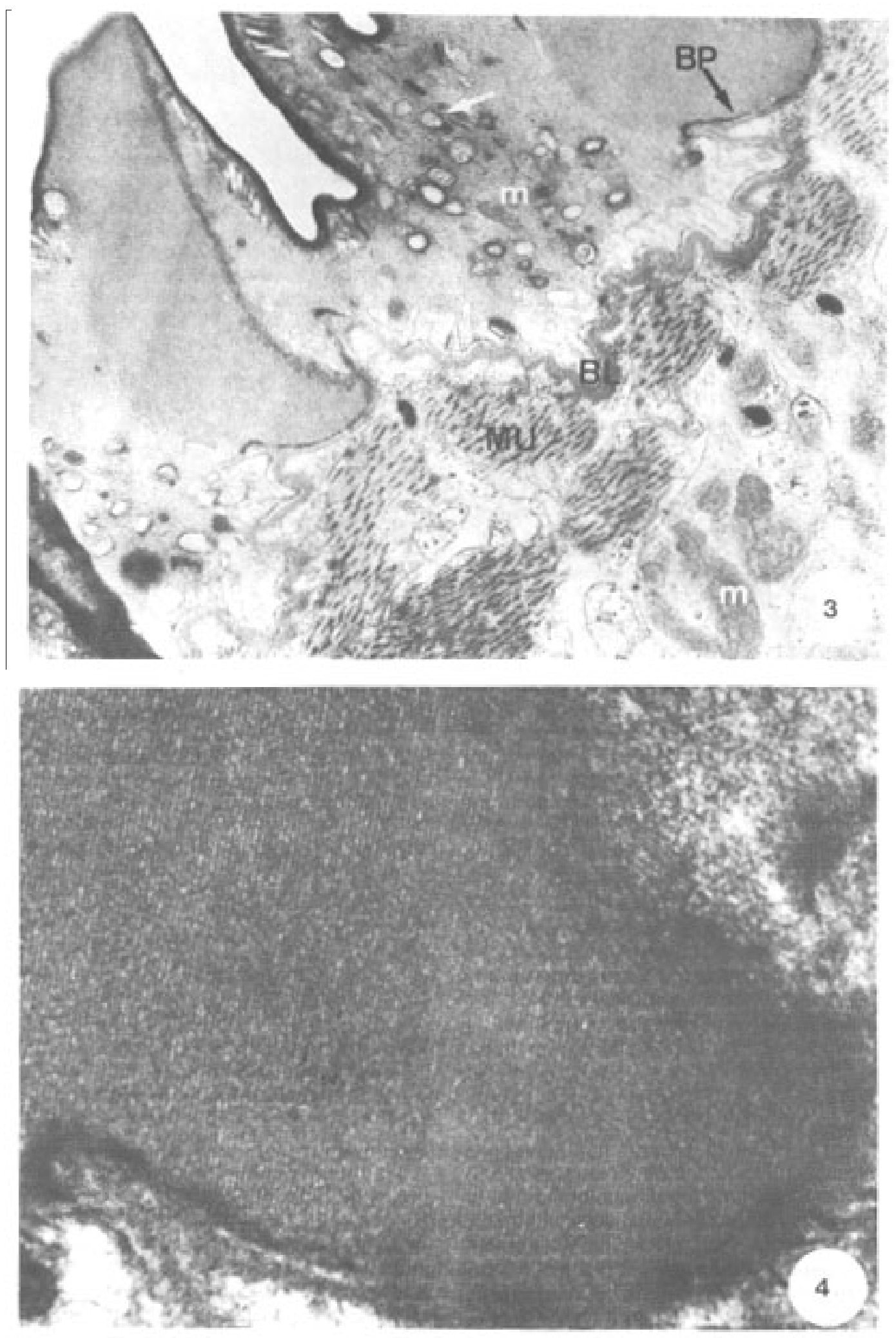

Fig. 3: syncytial layer with spines (S), basal plate (BP), inclusion bodies (white arrow), mitochondria (m), basal lamina (BL) and muscle fibres (MU). X 23,500. Fig. 4: high resolution of tegumental spine, showing the crystalline structure and basal plate (BP). X 100,000. 


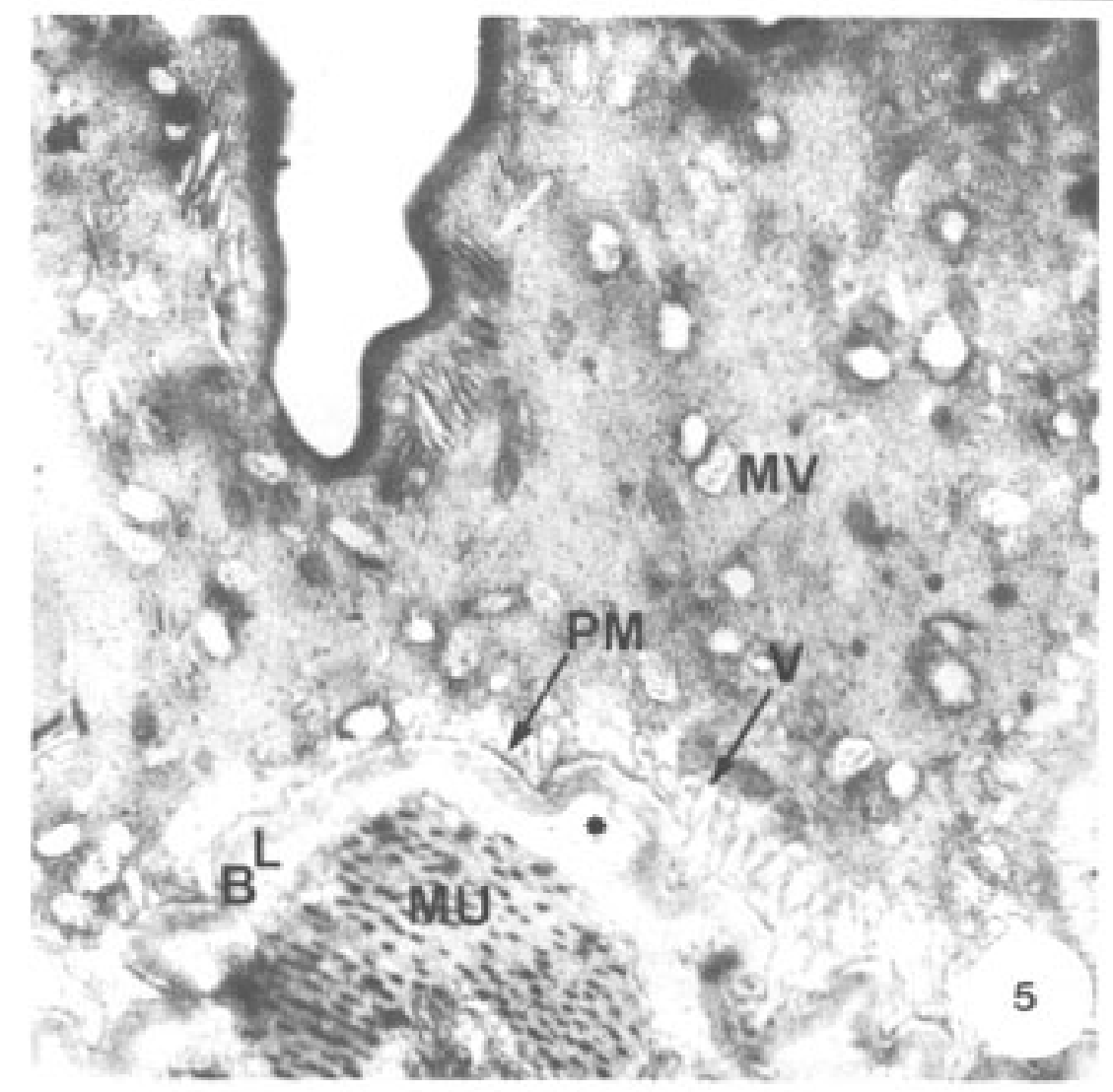

Fig. 5: detail of the tegument showing internal plasma membrane (PM) with invaginations forming vacuoles and vesicles (V), basal lamina (BL), interstitial material $\left(^{*}\right)$ and muscle fibres (MU). Observe the rod shaped bodies with their long axis perpendicular to the apical surface (white arrow) and multilamellate vesicles (MV). X 38,000.

were recognized in this tegumental layer, one consists of electrondense, long and thin, rod shaped bodies; most of them have their long axis perpendicular to the apical surface, but they are also found in the tegumental matrix, where they are randomly orientated (Fig. 5). The second type of inclusions consists of membrane-bound multilamellate vesicles. Approximately half of the vesicle interior appears like an empty space, the rest being filled with lamellae of electrondense material, separated by electrontranslucent gaps (Figs 3, 5).

A longitudinal section at the level of a tegumental papilla reveals the presence of a cillium, embedded in the syncytium in a protuberance with tegumental projections (Fig. 6). The presence of cilliated papillae in the tegument of $P$. arcuatus had been already demonstrated by scanning electron microscopy (Cohen et al. 1995).

The internal plasma membrane invaginates into the outer tegumental cytoplasm, by form of numerous folds, usually forming elongated vesicles (Fig. 5).

Basal lamina - The basal lamina, regularly thickened, follows the outline of the underlying musculature layer and is situated below the internal plasma membrane of the syncytium and separated from it by a narrow electron translucent space (Figs 3, 5, 7). Hemidesmosomes were observed connecting the internal plasma membrane with the basal lamina (Fig. 7). The fibrous interstitial material forms a thick layer beneath the basal lamina (Fig. 5).

Internal layer - The internal tegument consists of a distal layer of muscle cells and the mononucleated cell layer. The musculature consists of bundles of circular and longitudinally disposed muscle fibres, allowing the movements of body contraction and extension (Figs 1,2). The mononucleated cells are located below the musculature and are irregularly shaped. The small nuclei have an ondulated outline and contain a single large nucleolus as well as few irregular patches of chromatin. The nucleoplasm is filled by less dense chromatin granules (Fig. 1).

The cytoplasm of the internal tegumental cells presents free ribosomes, which pack the spaces 

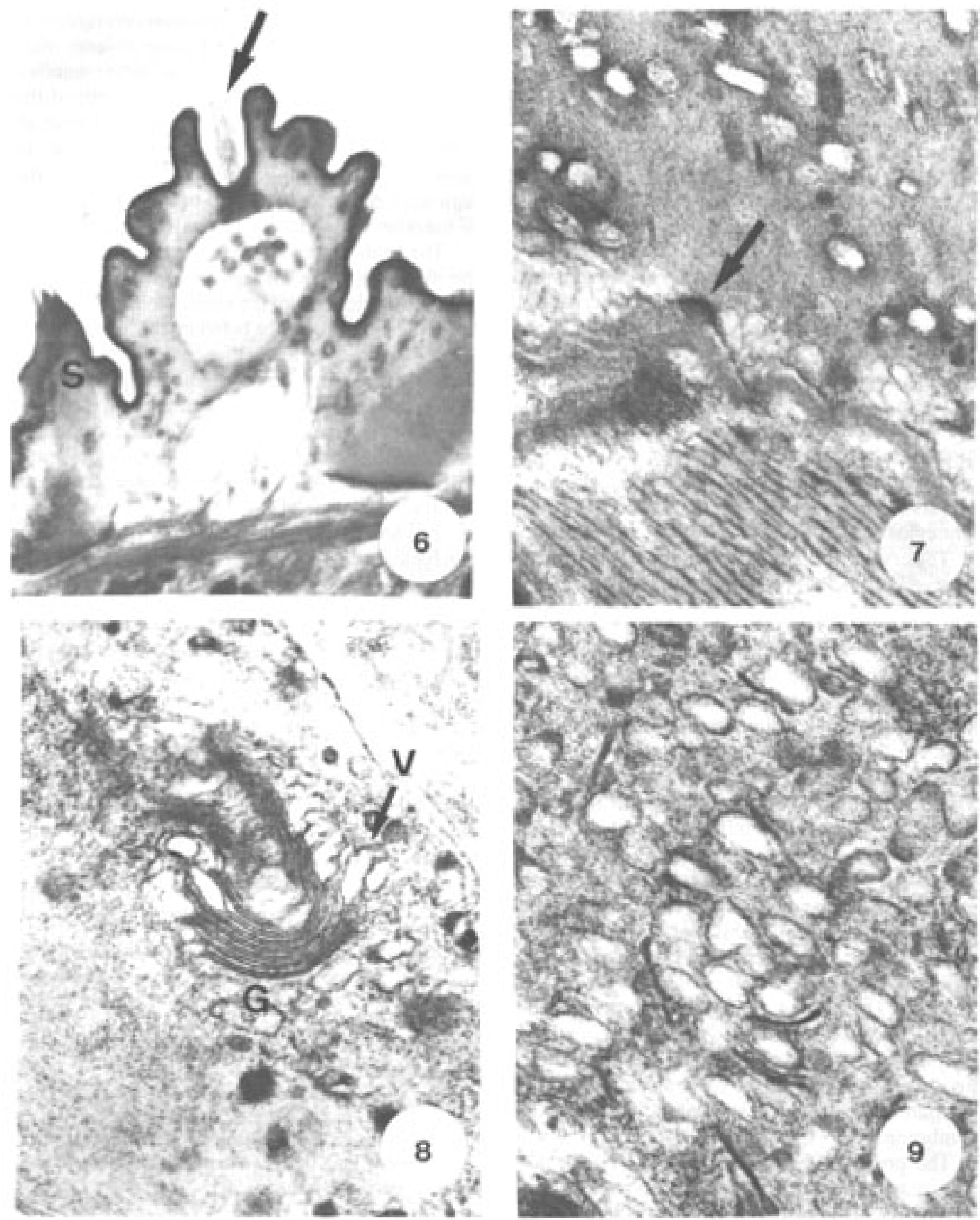

Fig. 6: detail of tegument showing sensorial papilla with cilium (arrow) and multipointed spine (S). X 12,000. Fig. 7: detail of tegument showing hemidesmosome (arrow) between basal lamina and internal plasma membrane. X 34,000. Fig. 8: tegumental cell presenting Golgi complex (G) with vesicles (V) in formation. X 37,000. Fig. 9: inclusion bodies of the tegumental cell. X 57,000.

between cell organelles and inclusion bodies (Fig. 9). These cells also contain one or more well developed Golgi stacks, consisting of approximately 5 to 7 flattened sacs in parallel, forming a slightly curved plaque and vesicles that arise from Golgi complex (Fig. 8). Variable shaped mitochondria are also observed and are usually larger than those in the external syncytial layer (Figs 2, 3). The two 
characteristic types of syncytial inclusions were also found in the cytoplasm of inner tegumental cells (Fig. 9).

Long and tenuous cytoplasmatic processes from the inner tegumental cells connect with the surface syncytium. These processes are filled with inclusion bodies and mitochondria and narrow in direction of the syncytial layer (Fig. 2).

\section{DISCUSSION}

The ultrastructural organization of the tegument of $P$. arcuatus is similar to previous descriptions of Digenea tegument studied by different authors (Threadgold 1968, Silk et al. 1969, Hockley 1973).

In Bucephalidae, ultrastructural studies of the tegument had been developed in larval forms by James et al. (1966), Higgins et al. (1977), Higgins (1980), Halton and Johnston (1982).

The irregular shaped surface of the tegument appears to be a constant feature and is not due to pynocytosis, as suggested by Burton (1964).

The crystalline structure of the spines were also observed in other larval and adult trematodes (Burton 1964, Koie 1971, Cohen et al. 1982, Zhou \& Podesta 1989). Cohen et al. (1982) suggested that the spines consist of hexagonally packed actin filaments and this suggestion was supported by other studies. According to Zhou and Podesta (1989), the spines may play an important role in the movement.

The inclusion bodies present in the surface syncytium are similar to those in the inner tegumental cells. The rod shaped bodies received different denominations as discoid granules (Wilson \& Barnes 1974), elongated bodies (Hockley \& Mc Laren 1973), dense bodies (Threadgold 1968) or disc-shaped bodies (Zdarska et al. 1990). The multilamellate vesicles had been called circular vesicles (Silk et al. 1969), spherical inclusions (Morris \& Threadgold 1968) or membranous bodies (Hockley \& Mc Laren 1973). According to the latter authors the rod shaped bodies contribute to the granular ground substance and the multilamellate vesicles contribute to the outer membrane.

The presence of mitochondria in the surface syncytium indicates that this layer possess metabolic activity energy-required. In P. arcuatus these mitochondria are smaller than those found in inner tegumental cells. The presence of mitochondria in the syncytial layer was also observed in other trematodes, like Opistorchis viverrini, studied by Apinhasmit et al. (1994). According to these authors, a greater amount of energy may be needed at the outer membrane and this energy is supported by mitochondria. Otherwise, in Orthocoelium scoliocoelium and Paramphistomum cervi (Sharma \& Hanna, 1988), mitochondria are absent; thus large quantities of amino acids and other metabolites are not taken up across the tegument of the rumen amphistomes. According to Brennan et al. (1991), the absence of mitochondria in Gastrodiscoides hominis would suggest that the tegument in this worm is also primarily protective in function with limited absorptive capacity.

The folds on the internal plasma membrane of the syncytial layer increase its surface area and reduce the thickness of the surface syncytium since they reduce the distance between the membranes. These fact leads to the evidence that the invaginations of the internal plasma membrane are involved in the passage of substances and that the inclusion bodies of the syncytial layer are formed from these invaginations, formerly synthetized in the inner tegumental cells and difused through the basal lamina.

The inner tegumental cells of $P$. arcuatus contain typical organelles of secretory cells. Some cells appear to be completely filled by inclusion bodies. According to Silk et al. (1969), this may be a result of sections through cells which are organized in such a way that not all of their contents are visible in a single plane. These observations confirm the hypothesis that in P. arcuatus only one type of tegumental cell is involved in the secretion of the syncytium.

The presence of free ribosomes, well developed Golgi complex, besides the secretory inclusion bodies in the inner tegumental cells and in the connections suggest that this inclusion bodies are there formed and pass up into the syncytial layer.

\section{REFERENCES}

Apinhasmit W, Sobhon P, Saitongdee P, Menayotin S, Upatham ES 1994. Opistorchis viverrini: Ultrastructure of the tegument of the first-week juveniles and adult flukes. Int J Parasitol 24: 613-621.

Brennan GP, Hanna REB, Nizami WA 1991. Ultrastructural and histochemical observations on the tegument of Gastrodiscoides hominis (Paramphistoma: Digenea). Int J Parasitol 21: 897-905.

Burton PR 1964. The ultrastructure of the integument of the frog lung fluke Haematoloechus medioplexus (Trematoda, Plagiorchiidae). J Morphol 115: 305318.

Cohen C, Reinhardt B, Castellani L, Norton P, Stirewalt M 1982. Schistosome surface spines are "crystals" of actin. J Cell Biol 95: 987-988.

Cohen SC, Kohn A, Barth OM 1995. Scanning electron microscopic study of Prosorhynchoides arcuatus (Linton, 1900) (Digenea: Bucephalidae). Mem Inst Oswaldo Cruz 90: 25-32.

Halton DW, Johnston BR 1982. Functional morphology of the metacercarial cyst of Bucephaloides 
gracilescens (Trematoda: Bucephalidae). Parasitology 85: 45-52.

Higgins JC 1980. Formation of the cyst wall and related changes in the structure of the tegument of Bucephalus haimeanus (Lacaze-Duthiers, 1854) during its metamorphosis from the cercarial to the metacercarial stage. Parasitology 81: 47-59.

Higgins JC, Wright DE, Matthews RA 1977. The ultrastructure and histochemistry of the cyst wall of Bucephalus haimeanus (Lacaze-Duthiers, 1854). Parasitology 75: 205-214.

Hockley DJ 1973. Ultrastructure of the tegument of Schistosoma. Adv Parasitol 11: 233-305.

Hockley DJ, Mc Laren DJ 1973. Schistosoma mansoni: changes in the outer membrane of the tegument during development from cercaria to adult worm. Int $J$ Parasitol 3: 13-25.

James BL, Bower EA, Richards JG 1966. The ultrastructure of the daughter sporocyst of cercaria Bucephalopsis haimeana Lacaze-Duthiers, 1854 (Digenea, Bucephalidae) from the edible cockle, Cardum edule L. Parasitology 56: 752-762.

Koie M 1971. On the histochemistry and ultrastructure of the tegument and associated structures of the cercaria of Zoogonoides viviparus in the first intermediate host. Ophelia 9: 165-206.
Morris GP, Threadgold LT 1968. Ultrastructure of the tegument of adult Schistosoma mansoni. J Parasitol 54: 15-27.

Sharma PN, Hanna REB 1988. Ultrastructure and cytochemistry of the tegument of Orthocoelium scoliocoelium and Paramphistomum cervi (Trematoda: Digenea). J Helminthol 62: 331-343.

Silk MH, Spence IM, Gear JHS 1969. Ultrastructural studies of the blood fluke - Schistosoma mansoni I. The integument. South Afr J Med Sci 34: 1-10.

Threadgold LT 1968. The tegument and associated structures of Haplometra cylindracea. Parasitology 58: 1-7.

Wilson RA, Barnes PE 1974. The tegument of Schistosoma mansoni: observations on the formation, structure and composition of cytoplasmatic inclusions in relation to tegument function. Parasitology 68: 239-258.

Zdarska Z, Soboleva TN, Valkounova J, Sterba J 1990. Ultrastructure of the general body tegument of the trematode Brachylaimus aequans. Helminthologia 27: 3-9.

Zhou Y, Podesta RB 1989. Surface spines of human blood flukes (Schistosoma mansoni) contain bundles of actin filaments having identical polarity. Eur $J$ Cell Biol 48: 150-153. 
470 TEM of Prosorhynchoides arcuatus - SC Cohen et al. 